\title{
Mixed mating in natural populations of the chestnut blight fungus, Cryphonectria parasitica
}

\author{
RE Marra ${ }^{1,3}$, P Cortesi $^{2}$, M Bissegger ${ }^{1}$ and MG Milgroom ${ }^{1}$ \\ ${ }^{1}$ Department of Plant Pathology, Cornell University, Ithaca, NY 14853, USA; ${ }^{2}$ Istituto di Patologia Vegetale, Università degli Studi di \\ Milano, 20133 Milan, Italy
}

\begin{abstract}
As in plants, fungi exhibit wide variation in reproductive strategies and mating systems. Although most sexually reproducing fungi are either predominantly outcrossing or predominantly selfing, there are some notable exceptions. The haploid, ascomycete chestnut blight pathogen, Cryphonectria parasitica, has previously been shown to have a mixed mating system in one population in USA. In this report, we show that both selfing and outcrossing occur in 10 additional populations of $C$. parasitica sampled from Japan, Italy, Switzerland and USA. Progeny arrays from each population were assayed for segregation at vegetative incompatibility (vic) and DNA fingerprinting loci. Outcrossing rates $\left(\hat{t}_{\mathrm{m}}\right)$ were estimated as the proportion of progeny arrays
\end{abstract}

showing segregation at one or more loci, corrected by the probability of nondetection of outcrossing $(\hat{\alpha})$. Estimates of $\hat{t}_{\mathrm{m}}$ varied from 0.74 to 0.97 , with the lowest rates consistently detected in USA populations $(0.74-0.78)$. Five populations (four in USA and one in Italy) had $\hat{t}_{\mathrm{m}}$ significantly less than 1 , supporting the conclusion that these populations exhibit mixed mating. The underlying causes of variation in outcrossing rates among populations of $C$. parasitica are not known, but we speculate that - as in plants - outcrossing is a function of ecological, demographic and genetic factors.

Heredity (2004) 93, 189-195, advance online publication, 26 May 2004; doi:10.1038/sj.hdy.6800492

Keywords: fungal mating system; mixed mating system; outcrossing; reproductive biology; selfing; self-fertilization

\section{Introduction}

Mating systems have long intrigued biologists, perhaps in large part due to the interplay between mating system and life history, and the profound effects that differing modes of reproduction can have on population genetic structure. Early observations of plant breeding systems categorized species as being either predominantly selfing or predominantly outcrossing (reviewed in Schemske and Lande, 1985), and early models concerned with mating system evolution concluded that only complete selfing and complete outcrossing are evolutionarily stable, dependent on the frequency with which mutational load is purged (Jain, 1976; Lande and Schemske, 1985). Subsequent studies revealed species and populations with apparently stable intermediate levels of selfing (mixed mating systems) (Waller, 1986; Barrett and Eckert, 1990), stimulating interest in the evolutionary forces that might maintain them, such as spatial genetic structure (Holsinger, 1986; Uyenoyama et al, 1993; Ronfort and Couvet, 1995), inbreeding depression (Charlesworth and Charlesworth, 1987, 1990; Charlesworth et al, 1990; Uyenoyama et al, 1993) and identity disequilibria, that is, associations between viability loci and mating system loci (Charlesworth and Charlesworth, 1990; Holsinger, 1991; Uyenoyama et al, 1993). However, it appears that

Correspondence: MG Milgroom, Department of Plant Pathology, Cornell University, Ithaca, NY 14853, USA.

${ }^{3}$ Current address: Department of Plant Pathology and Ecology, Connecticut Agricultural Experiment Station, New Haven, CT 06504, USA.

E-mail:mgm5@cornell.edu

Received 9 June 2003; accepted 29 March 2004; published online 26 May 2004 outcrossing rates are not static properties of species, but rather that outcrossing rates can vary intraspecifically, among individuals and among populations, in response to a range of genetic and environmental factors (Barrett and Eckert, 1990; Richards, 1997).

As with early studies on plants, most fungi studied to date have been classified as being either self-compatible or self-incompatible, corresponding roughly to the terms 'homothallic' and 'heterothallic' that are used in mycology (given the parallels between plant and fungal mating systems, we prefer the former pair of terms because they are well established in the literature on plant mating systems). However, in contrast with the majority of plant mating system studies, most fungal mating system studies have been conducted in the laboratory, and have not considered the degree to which mating behavior in the laboratory may differ from mating behavior in natural populations. Of the few studies of fungal mating systems in natural populations, most have conformed more or less to laboratory results: self-compatible species predominately selfed and self-incompatible species predominately outcrossed (Ainsworth, 1987; Ennos and Swales, 1987; Sharland et al, 1988; Sharland and Rayner, 1989a,b; Adams et al, 1990; Kohn et al, 1991; Kohli and Kohn, 1992; Wang, 1997; Cortesi and Milgroom, 2001; Kroken, 2001), with several exceptions (see below). However, some fungal species deviate from the strict dichotomy between self-compatibility and self-incompatibility (Mathieson, 1952; Uhm and Fujii, 1983; Perkins, 1987; Herskowitz, 1988; Harrington and McNew, 1997), supporting the need for a broader perspective on fungal mating systems.

Although most field studies of fungal mating systems have confirmed laboratory observations, several 
exceptions are worth noting. In the laboratory, the woodrotting fungus, Phellinus nigrolimitatus, is self-compatible (Fischer, 1996; Kauserud and Schumacher, 2001), in contrast with a field study that showed nearly complete outcrossing (Kauserud and Schumacher, 2001). In laboratory matings, California isolates of Fusarium circinatum, the causal agent of pitch canker disease, predominately outcrossed, even though California populations consist almost entirely of clonally propagating lineages, and no sexual structures have been reported in nature (Wikler and Gordon, 2000; Wikler et al, 2000). The anther-smut pathogen, Microbotryum violaceum, has a genetic self-incompatibility system, yet there is little evidence for outcrossing, and most matings occur as intratetrad 'diploid selfing' between sibling haploid meiospores (Kaltz and Shykoff, 1999; Hood and Antonovics, 2000). Another example of discord between laboratory and field observations is seen in the mating system of the ascomycete chestnut blight fungus, Cryphonectria parasitica. In the laboratory, C. parasitica has a genetic self-incompatibility system similar to that of other self-incompatible ascomcyetes (Marra and Milgroom, 2001). In this mating system (referred to as a bipolar mating system), a single mating-type locus (MAT) is biallelic, such that successful mating occurs only between individuals with opposite MAT alleles (Marra and Milgroom, 2001). Contrary to the observed self-incompatibility in the lab, some isolates that failed to self-fertilize in the laboratory have been shown to selffertilize in the field (Marra and Milgroom, 2001). Furthermore, in a field population in Mountain Lake, Virginia, C. parasitica was estimated to have an outcrossing rate of $73 \%$, which is significantly less than 1 (Milgroom et al, 1993). Thus, although C. parasitica is almost exclusively outcrossing in the laboratory, it appears to have the potential for mixed mating in nature.

The purpose of the research reported here was to estimate the mating system of $C$. parasitica in additional natural populations. Specifically, our objectives were to test the hypothesis that self-fertilization occurs in all $C$. parasitica populations - that is, that it is an important and relevant component of the $C$. parasitica mating system and to assess variability in outcrossing rates among populations. Our overall strategy was to repeat the types of mating system estimates made in Virginia (Milgroom et al, 1993) in multiple populations from three continents. To accomplish this objective, we estimated the outcrossing rates in field populations of C. parasitica in USA, Europe and Japan, representing a broad geographic distribution of C. parasitica.

\section{Materials and methods}

\section{Study organism}

The reproductive biology of $C$. parasitica was described in detail previously (Milgroom et al, 1993; Marra and Milgroom, 2001). C. parasitica is a haploid filamentous fungus for most of its life cycle. It colonizes wounds in the bark of chestnut trees (Castanea spp.), invading and destroying cambial tissues, resulting in cankers on the trees, symptomatic of chestnut blight. Cankers, which consist of both fungal tissue (stroma, pl. stromata) and bark, are the site of sporogenesis of asexual spores (conidia) as well as sexual spores (ascospores). Asco- spores are found in flask-shaped fruiting bodies (perithecia), each containing the progeny from a single mating (Milgroom et al, 1993).

\section{Populations sampled}

C. parasitica was sampled from a total of 10 populations from USA, Italy, Switzerland and Japan to estimate outcrossing rates (Table 1). In each population, $C$. parasitica was sampled from cankers on chestnut trees by removing small pieces of bark containing stromata. Only one canker was sampled from each single tree in most populations, although multiple cankers on the same trees were sampled from Depot Hill and Danby, New York, USA. Unless noted otherwise, we sampled only one perithecium from each bark sample, and from each perithecium we obtained at least eight single ascospore progeny, constituting the progeny array, as described previously (Milgroom et al, 1993). In addition, for most progeny arrays we sampled maternal genotypes by culturing from mycelium surrounding the sampled perithecium. Perithecia from two US populations (Danby and Depot Hill) were sampled from populations that had been studied intensively for spatial genetic structure (Milgroom and Lipari, 1995). West Virginia populations Parsons-1 and Parsons-2 were sampled from American chestnut, Castanea dentata, in September 1993 from 10year-old clearcut plots, each of approximately $1500 \mathrm{~m}^{2}$, in the Monongahela National Forest, in Parsons Township, West Virginia. We sampled perithecia from European chestnut, Castanea sativa, in four populations from stromata originally sampled for estimates of genetic diversity (Cortesi et al, 1996; Bissegger et al, 1997). Populations in Japan were sampled from orchards of Japanese chestnut, Castanea crenata, in April 1998 in Okoba, Kumamoto Prefecture in southern Japan and Chudai, Kyoto Prefecture in central Japan (Liu et al, 2003).

Nearly all cankers sampled from USA and European populations had perithecia containing viable ascospore progeny. However, we were able to recover viable progeny from fewer than half of the cankers from the two Japanese populations, sampling progeny from 16 and 12 perithecia in Okoba and Chudai, respectively.

\section{Distinguishing selfing from outcrossing}

Selfing and outcrossing were determined for each progeny array essentially as described previously (Milgroom et al, 1993). For the two Japanese populations, we assayed only for segregation of vegetative incompatibility (vic) alleles. Vegetative incompatibility is a self/ nonself recognition system controlled by at least six unlinked vic loci (Cortesi and Milgroom, 1998) and is assayed using methods described previously (Cortesi et al, 1996). For the Italian and Swiss populations, we assayed first for segregation of alleles at vic loci, and subsequently for segregation of alleles at DNA fingerprint (fp) loci. Assays for vic segregation were carried out first because they are relatively simple, requiring only culturing and not DNA extractions/manipulations, thereby limiting the number of fingerprinting assays that needed to be carried out subsequently. Progeny arrays for which vic segregation was not observed were further tested by a DNA fingerprinting method (Milgroom et al, 1992), which involves probing gel blots with 
a transposable element (Linder-Basso et al, 2001) that occurs in multiple copies dispersed throughout the $C$. parasitica genome. DNA fingerprinting by this method detects the presence or absence of highly polymorphic restriction fragments at multiple independent loci (Milgroom et al, 1992). For the four North American populations (Danby, Depot Hill, Parsons-1 and Parsons2), all progeny arrays were fingerprinted, but not assayed for vic segregation; a previous study showed that outcrossing could be detected more often by fingerprinting than by vegetative incompatibility (Milgroom et al, 1993). Segregation at either vic or fp loci in each progeny array was interpreted as evidence for outcrossing (Milgroom et al, 1993). As vic and fp allele segregation will be 1:1 among progeny from a single perithecium (Cortesi and Milgroom, 1998; Milgroom et al, 1992), we have a probability of $>99 \%$ of detecting outcrossing with as few as eight progeny per perithecium $\left(1-(0.5)^{8}=0.996\right)$.

In the Parsons- 1 and Parsons- 2 samples, we used an alternative DNA fingerprinting method. Instead of fingerprinting individual progeny, we cultured single progeny within an array independently, pooled tissue from these progeny, extracted DNA from the pooled sample and fingerprinted the pooled DNA. The composite fp (from the pooled sample) was then compared to the maternal $\mathrm{fp}$. Outcrossing was determined by the presence of bands on autoradiographs in the composite $\mathrm{fp}$ that were not present in the maternal $\mathrm{fp}$. We also used this method for five progeny arrays from each of the Bergamo and Crevoladossola samples. All fingerprinting was carried out using standard methods (Milgroom et al, 1992).

\section{Estimation of outcrossing rates}

The outcrossing rate was first estimated simply as the proportion of progeny arrays that segregated at vic and/ or DNA fp loci within each sample. In Japan, almost every isolate of C. parasitica within a chestnut orchard, including 28 isolates in Chudai, was vegetatively incompatible with every other isolate (Y-C Liu and MG Milgroom, unpublished); therefore, assays for segregation at vic loci have a very high probability of detecting all outcrosses (Milgroom et al, 1993). However, for the USA and European populations, which have lower vic genotype diversity (Milgroom and Cortesi, 1999), we estimated the probability of not detecting an outcrossed progeny array using the method of Shaw et al (1981), modified for haploids (Milgroom et al, 1993). Briefly, the probability estimate $(\hat{\alpha})$ calculates the likelihood that outcrossing between maternal and paternal gametes will not be detected because they share the same alleles at the assayed loci; this likelihood decreases as the number of loci and the number of alleles per locus increase, and also as allelic frequencies become nearly equal to each other. For our analyses, we assumed that the maternal and paternal pools had identical allele frequencies. We base this assumption on the fact that C. parasitica is hermaphroditic, with both male and female structures almost always present together in a single stroma. To calculate for European populations (Bergamo, Crevoladossola, Gnosca and Lumino), we used two sets of data: estimates of vic allele frequencies (Milgroom and Cortesi, 1999) as well as fps of randomly sampled canker isolates (100 from Bergamo, 100 from Crevoladossola, 31 from Gnosca and 65 from Lumino). For Danby and Depot Hill, we estimated $\mathrm{fp}$ allele frequencies using $\mathrm{fp}$ data obtained previously (Milgroom and Lipari, 1995).

To calculate $\hat{\alpha}$ in the WV populations, Parsons- 1 and Parsons-2, which were assayed by pooling progeny, we used DNA fp data from 18 maternal isolates from the Parsons-2 population. In comparing the composite progeny $\mathrm{fp}$ to the maternal $\mathrm{fp}$, segregation will only be detected at loci with a dominant allele (presence of $\mathrm{fp}$ band) in the paternal isolate and recessive allele (absence of $\mathrm{fp}$ band) in the maternal isolate; segregating loci with dominant alleles in the maternal isolate will not be detected in the pooled progeny $\mathrm{fp}$ because they will appear the same as the maternal $\mathrm{fp}$. In order to adjust for this pooled method, we calculated the probability of nondetection for each maternal isolate based only on loci for which that maternal $\mathrm{fp}$ had the recessive allele, and then taking the average of these probabilities for the population.

\section{Results}

We observed both selfing and outcrossing in all 10 populations of $C$. parasitica, from three continents (Table 1). Segregation of DNA fp alleles, or DNA fp alleles in combination with vic alleles, was used to distinguish outcrossing from selfing in European and USA populations. In the European populations, segregation of vic alleles identified some, but not all, outcrossing. The estimated probabilities of not detecting outcrossing by vic segregation alone $\left(\hat{\alpha}_{\text {vic }}\right)$ ranged from 10 to $21 \%$ (Table 1). When progeny arrays that failed to segregate for vic were fingerprinted, segregation was evident in an additional 15-38\% of the arrays in the four European populations. Based on genotypic and allelic diversity of DNA fp loci in Europe and USA, we infer that segregation of $\mathrm{fp}$ alleles identifies almost all outcrosses in these samples. The probabilities of nondetection of outcrossing by fp segregation $\left(\hat{\alpha}_{\mathrm{fp}}\right)$ was $\leq 0.0063$ in all populations, so that corrected outcrossing estimates $\left(\hat{t}_{\mathrm{m}(\mathrm{fp})}\right)$ were only negligibly greater than uncorrected estimates $\left(\hat{t}_{\mathrm{fp}}\right)$ (Table 1$)$. Estimates of outcrossing in European and USA populations ranged from 0.74 to 0.97 . All four USA populations and the Italian population Crevoladossola had outcrossing estimates significantly less than 1. Therefore, we conclude that these five populations provide definitive evidence for the occurrence of mixed mating.

To estimate outcrossing in the two Japanese populations, we used only vic segregation data. We found only one of $12(8 \%)$ and two of $16(12 \%)$ progeny arrays from Chudai and Okoba, respectively, that did not segregate at vic loci, resulting in uncorrected outcrossing estimates $\left(\hat{t}_{\text {vic }}\right)$ of 0.92 and 0.88 , respectively. We do not know the vic genotypes or allele frequencies in Japanese populations, as we do in Europe or USA (Milgroom and Cortesi, 1999), and therefore we could not correct estimates for nondetection of outcrossing. Neither of these estimates is significantly less than 1 (the $95 \%$ confidence interval (CI) included 1; Table 1).

\section{Discussion}

Our study of 10 populations from three continents suggests that mixed mating is a regular feature of the 
Table 1 Outcrossing estimates $\hat{t}$ for C. parasitica in populations from three continents

\begin{tabular}{|c|c|c|c|c|c|c|c|c|c|c|c|c|}
\hline \multirow[t]{2}{*}{ Population } & \multirow[t]{2}{*}{$\mathrm{N}$} & \multirow{2}{*}{$\begin{array}{l}\text { Number of progeny } \\
\text { arrays with no } \\
\text { segregation }\end{array}$} & \multicolumn{5}{|c|}{ vic loci } & \multicolumn{5}{|c|}{ DNA fingerprint loci } \\
\hline & & & $\begin{array}{l}\text { Number of } \\
\text { progeny arrays } \\
\text { segregating } \\
\text { at vic loci }\end{array}$ & Uncorrected $\hat{t}_{v i c}$ & $\hat{\alpha}_{v i c}$ & $\hat{\mathrm{t}}_{m(v i c)}$ & $95 \%$ CI for $\hat{\mathrm{t}}_{m(v i c)^{\mathrm{a}}}$ & $\begin{array}{l}\text { Number of progeny } \\
\text { arrays segregating at } \\
\text { DNA fingerprint loci }\end{array}$ & Uncorrected $\hat{\mathrm{t}}_{f p}$ & $\hat{\alpha}_{\mathrm{fp}}$ & $\hat{\mathrm{t}}_{m(f p)}$ & $95 \% C I$ for $\hat{\mathrm{t}}_{m(f p)}$ \\
\hline Bergamo, Italy & 31 & 3 & 23 & 0.74 & 0.214 & 0.94 & $(0.86,1.03)$ & $5^{\mathrm{b}, \mathrm{d}, \mathrm{e}}$ & 0.90 & 0.0030 & 0.91 & $(0.80,1.01)$ \\
\hline Crevoladossola, Italy & 25 & 5 & 17 & 0.68 & 0.198 & 0.85 & $(0.71,0.99)^{*}$ & $3^{\mathrm{b}, \mathrm{d}, \mathrm{e}}$ & 0.80 & 0.0017 & 0.80 & $(0.65,0.96)^{*}$ \\
\hline Gnosca, Switzerland & 27 & 3 & 16 & 0.59 & 0.099 & 0.66 & $(0.48,0.83)^{*}$ & $8^{\mathrm{b}, \mathrm{d}}$ & 0.89 & 0.0007 & 0.89 & $(0.77,1.01)$ \\
\hline Lumino, Switzerland & 30 & 1 & 18 & 0.60 & 0.144 & 0.70 & $(0.54,0.87)^{*}$ & $11^{\mathrm{b}, \mathrm{d}}$ & 0.97 & 0.0002 & 0.97 & $(0.91,1.03)$ \\
\hline Danby, NY, USA & 20 & 5 & - & - & - & - & - & $15^{\mathrm{c}, \mathrm{d}}$ & 0.75 & 0.0002 & 0.75 & $(0.56,0.92)^{*}$ \\
\hline Depot Hill, NY, USA & 56 & 13 & - & - & 0.057 & - & - & $43^{c, d}$ & 0.74 & 0.0001 & 0.74 & $(0.63,0.86)^{*}$ \\
\hline Parsons-1, WV, USA & 22 & 5 & - & - & - & - & - & $17^{\mathrm{c}, \mathrm{f}}$ & 0.77 & 0.0063 & 0.78 & $(0.60,0.95)^{*}$ \\
\hline Parsons-2, WV, USA & 22 & 5 & - & - & - & - & - & $17^{\mathrm{c}, \mathrm{f}}$ & 0.77 & 0.0063 & 0.78 & $(0.60,0.95)^{*}$ \\
\hline Chudai, Japan & 12 & 1 & 11 & 0.92 & - & - & $(0.70,1.07)^{\mathrm{g}}$ & - & - & - & - & - \\
\hline Okoba, Japan & 16 & 2 & 14 & 0.88 & - & - & $(0.71,1.04)^{\mathrm{g}}$ & - & - & - & - & - \\
\hline
\end{tabular}

Estimates $\hat{t}_{\mathrm{m}}$ were corrected for the probability of nondetection of outcrossing ( $\left.\hat{\alpha}\right)$ (Shaw et al, 1981; Milgroom et al, 1993) for vic and DNA fp markers.

${ }^{*} \hat{t}_{\mathrm{m}} \neq 1$ at $95 \%$ level of significance.

a95\% CI $=\hat{t}_{\mathrm{m}} \pm 1.96 \sqrt{\left(\hat{t}_{\mathrm{m}}\right)\left(1-\hat{t}_{\mathrm{m}}\right) / n}$.

'Only progeny arrays showing no segregation at vic loci were fingerprinted.

cAll progeny arrays were fingerprinted.

'Based on DNA fingerprints of at least eight individual ascospore progeny per perithecium.

eFive progeny arrays fingerprinted by pooled method (see text).

${ }^{\mathrm{f}}$ All progeny arrays fingerprinted by pooled method (see text).

895\% CIs for Chudai and Okoba are based on uncorrected $\hat{t}_{\text {vic. }}$ 
C. parasitica mating system, confirming an earlier finding from a single USA population (Milgroom et al, 1993). We found evidence for selfing, that is, at least one progeny array lacking in segregation of highly polymorphic genetic markers, in all 10 populations. Although it would be correct to define mixed mating as any amount of selfing occurring in an otherwise outcrossing population, we believe it is appropriate to classify as mixed mating only those populations in which the frequency of selfing has the potential to significantly impact population genetic structure (notwithstanding the potential to achieve the same results through biparental inbreeding in completely outcrossing populations). Therefore, we considered mixed mating to have occurred when outcrossing rates were significantly less than 1. Five populations - all four USA populations as well as one from Italy - had outcrossing rates significantly less than 1, ranging from 0.74 (Depot Hill, NY, USA) to 0.80 (Crevoladossola, Italy), and can therefore be classified by our criteria as having undergone mixed mating. Estimates of outcrossing in USA populations were remarkably similar to each other (0.74-0.78) and to an estimate made previously in Mt Lake, VA, USA (0.73) (Milgroom et al, 1993). Outcrossing rates in the remaining five populations ranged from 0.88 (Okoba, Japan) to 0.97 (Lumino, Switzerland) and were not significantly less than 1. We conclude from this study that C. parasitica regularly undergoes selfing and that mixed mating is commonly found in natural populations.

The observation of mixed mating in populations of C. parasitica is of considerable interest to the fields of mycology and evolution. To date, there have been few studies of fungal mating systems as they manifest in natural populations, in contrast with the extensive body of research on plant mating systems. In a reanalysis of data on 129 plant species, Barrett and Eckert (1990) observed a bimodal distribution of outcrossing rate in plants: $23 \%$ of the species had outcrossing rates of $20 \%$ or less, $43 \%$ had outcrossing rates of $80 \%$ or more, leaving $36 \%$ of the species with intermediate levels of outcrossing, between $20 \%$ and $80 \%$. Models concerned with the evolutionary stability of mixed mating systems in plants have not been evaluated for their relevance to fungi, which though similar to plants in some respects also differ significantly from plants in other respects. Most mixed mating system models have centered on a balance between two somewhat opposing forces, the advantages of selfing and inbreeding depression (Schemske and Lande, 1985; Barrett and Eckert, 1990). As C. parasitica, like most ascomycetous fungi, is haploid for most of its life cycle, the degree to which inbreeding depression plays a role in shaping $C$. parasitica's mating system is uncertain. Interestingly, Leslie and Raju (1985) uncovered deleterious and recessive alleles at numerous loci among wild isolates of the ascomycete Neurospora crassa. Therefore, because the brief diploid phase of ascomycetes is essential to mating and reproduction, inbreeding depression may be an important selective force counteracting and perhaps balancing factors that promote selfing.

Estimates of outcrossing rely on the detection of segregating genetic markers among progeny. In $C$. parasitica, we used two multilocus marker systems, vegetative incompatibility (Cortesi et al, 1996; Cortesi and Milgroom, 1998) and DNA fingerprinting (Milgroom et al, 1992; Milgroom et al, 1993). Assaying for segregation of vic alleles is much faster and less expensive than DNA fingerprinting because it involves only culturing the fungus (Cortesi et al, 1996). In Japanese populations, vic markers were sufficient to identify most outcrossing with high probability because of very high diversity of vic genotypes (Y-C Liu and MG Milgroom, unpublished data). In contrast, vic is not a reliable marker for detecting outcrossing in European populations because of lower vic allelic and genotypic diversity (Milgroom and Cortesi, 1999). In each of the four European populations, the estimated nondetection probability (Shaw et al, 1981; Milgroom et al, 1993) based on vic allele frequencies $\left(\hat{\alpha}_{\text {vic }}\right)$ was $10-21 \%$. In reality, vic segregation failed to detect 15$38 \%$ of the outcrossed progeny arrays that segregated for DNA fp markers. For Bergamo and Crevoladossola, $\hat{t}_{\mathrm{m} \text { (vic) }}$ (0.94 and 0.85 , respectively) is not significantly different than $\hat{t}_{\mathrm{m}(\mathrm{fp})}(0.91$ and 0.80 , respectively). However, for both Lumino and Gnosca, $\hat{t}_{\mathrm{m} \text { (vic) }}(0.70$ and 0.66 , respectively) is significantly lower than $\hat{t}_{\mathrm{m}(\mathrm{fp})}(0.97$ and 0.89 , respectively). The consequence of the difference in estimates for these populations is that in the former two we would conclude mixed mating, whereas in the latter two we would not. Although we did not use vic markers in the four populations in USA, vic allelic and genotypic diversity are typically higher than in European populations of C. parasitica (Milgroom and Cortesi, 1999); for example, the estimated nondetection probability in Depot Hill was $\hat{\alpha}_{\text {vic }} \approx 6 \%$. As vic diversity in Depot Hill is representative of other USA populations (Milgroom and Cortesi, 1999), a vic-based estimate corrected by $\alpha$ may be adequate as the sole estimator of outcrossing rates in USA.

Estimates of outcrossing rates varied considerably among populations. We do not yet know the mechanisms underlying these differences. However, plant mating system studies have shown that variation in outcrossing rates can be due to genetic (Lloyd, 1967; Vasek and Harding, 1976; Schoen, 1982; Schemske and Lande, 1985; Barrett and Shore, 1987; Barrett and Eckert, 1990; Lipow et al, 1999; Pascarella, 1997), demographic (Murawski and Hamrick, 1991; Karron et al, 1995) and/or environmental (Brown et al, 1978; Shea, 1987) factors. Among the 10 C. parasitica populations in our study, we observed outcrossing rates that varied from 0.74 to 0.97 , with a mean of 0.84 . Similar ranges in outcrossing rates among populations have been observed in several plant species. Ellstrand et al (1978) found outcrossing rates between 0.54 and 0.91 among 10 populations of sunflower, Helianthus annuus, and that outcrossing rate varied inversely with plant density. In contrast, outcrossing rates ranging from 0.62 to 0.98 of populations of buck's horn plantain, Plantago coronopus, correlated positively with plant density (Wolff et al, 1988). However, much lower outcrossing rates were reported among populations of Lycopersicon pimpinellifolium, ranging from 0.00 to 0.40 , with outcrossing rate correlating positively with genetic variation for flower size (Rick et al, 1978). A negative correlation between altitude and outcrossing rates was observed in balsam fir, Abies balsamea (Neale and Adams, 1985).

We speculate that there are analogous genetic, demographic and/or environmental components underlying outcrossing rate variation in fungal mating systems, although given the paucity of such studies in fungi, this 
remains an open and intriguing area of study. In $C$. parasitica, potential genetic factors that facilitate or inhibit selfing cannot be studied in the laboratory, where the fungus exhibits a typical ascomycete bipolar self-incompatibility system, and selfing occurs very rarely (Marra and Milgroom, 2001). Furthermore, the mechanism by which self-incompatibility is bypassed in order for selfing to occur has not yet been completely resolved. In 'homothallic' fungi, selfing typically requires both mating types, with both mating-type idiomorphs closely linked or fused on the same chromosome (Yun et al, 1999). However, this model for fungal self-compatibility has not been borne out in our previous studies of C. parasitica. C. parasitica appears to have two different mechanisms for selfing (McGuire et al, 2004). The more common of the two suggests automixis, and involves the presence of both mating-type idiomorphs in different and otherwise isogenic nuclei of the same individual, as heterokaryons. However, some selfing C. parasitica isolates have only one mating type or the other, and may be apomictic rather than meiotic (McGuire et al, 2004). The disparity in C. parasitica's propensity to self in the field versus the laboratory suggests that demography and/or environment may influence variation in outcrossing rates. It is difficult to determine from the current study the demographic or environmental factors that lead to selfing because $C$. parasitica was sampled from three different Castanea species, on the three continents, growing in conditions varying from understory chestnut trees in various hardwood forests in the USA, to managed chestnut forests in Europe, to orchards for nut production in Japan. However, it may be possible to assess the effects of genetics, demography and environment on the mating system under field conditions, where we showed previously that isolates that would not self in the lab selfed readily in nature (Marra and Milgroom, 2001). Testing specific hypotheses will require inoculations of the same $C$. parasitica genotypes onto chestnut trees in the field under different demographic and environmental conditions. Studies to address these types of questions are currently underway in order to quantify environmental and genetic effects on mixed mating.

In conclusion, self-fertilization was observed in all 10 populations, confirming an earlier report of mixed mating $\left(\hat{t}_{\mathrm{m}(\mathrm{fp})}=0.73\right)$ in a single population in USA (Milgroom et al, 1993). Outcrossing rates in five populations - Danby, NY, USA; Depot Hill, NY, USA; Parsons-1, WV, USA; Parsons-2, WV, USA; and Crevoladossola, Italy - were significantly less than 1, leading to a conclusion of mixed mating in these five populations. These outcrossing estimates were notably lower $(0.74$ 0.80) than outcrossing rates observed in the remaining five populations from Italy, Switzerland and Japan (0.890.97). Nonetheless, selfing appears to be an important component of mating in C. parasitica in nature, a finding of particular interest given the robust genetic selfincompatibility system observed in the laboratory (Marra and Milgroom, 2001).

\section{Acknowledgements}

We thank P Campbell, J Elias, S Lipari and C Schneider for assistance in the field and laboratory, and William MacDonald for facilitating the collections in West
Virginia. We also thank Monica Geber, Tobin Peever and John Willis for critical reading of the manuscript. This study was funded in part by National Science Foundation Grant No. DEB-9707675 to MGM and REM; US Department of Agriculture, National Research Initiative Competitive Grants Program Grant No. 97-353034536 to MGM; North Atlantic Treaty Organization Cooperative Research Grant No. 930930 to MGM and PC; and a postdoctoral fellowship from the Swiss National Science Foundation to MB.

\section{References}

Adams G, Hammer S, Proffer T (1990). Vegetative compatibility in Leucostoma persoonii. Phytopathology 80: 287-291.

Ainsworth AM (1987). Occurrence and interactions of outcrossing and non-outcrossing populations in Stereum, Phanerochaete, and Coniophora. In: Rayner ADM, Brasier CM, Moore D (eds) Evolutionary Biology of the Fungi. Cambridge University Press: Cambridge.

Barrett SCH, Eckert CG (1990). Variation and evolution of mating systems in seed plants. In: Kawano S (ed) Biological Approaches and Evolutionary Trends in Plants. Academic Press: London, pp 229-254.

Barrett SCH, Shore JS (1987). Variation and evolution of breeding systems in the Turnera ulmifolia L. complex (Turneraceae). Evolution 41: 340-354.

Bissegger M, Rigling D, Heiniger U (1997). Population structure and disease development of Cryphonectria parasitica in European chestnut forests in the presence of natural hypovirulence. Phytopathology 87: 50-59.

Brown AHD, Zohary D, Nevo E (1978). Outcrossing rates and heterozygosity in natural populations of Hordeum spontaneum Koch in Israel. Heredity 41: 49-62.

Charlesworth D, Charlesworth B (1987). Inbreeding depression and its evolutionary consequences. Annu Rev Ecol Syst 18: 237-268.

Charlesworth D, Charlesworth B (1990). Inbreeding depression with heterozygote advantage and its effect on selection for modifiers changing the outcrossing rate. Evolution 44: 870-888.

Charlesworth D, Morgan MT, Charlesworth B (1990). Inbreeding depression, genetic load, and the evolution of outcrossing rates in a multilocus system with no linkage. Evolution 44: 1469-1489.

Cortesi P, Milgroom MG (1998). Genetics of vegetative incompatibility in Cryphonectria parasitica. Appl Environ Microbiol 64: 2988-2994.

Cortesi P, Milgroom MG (2001). Outcrossing and diversity of vegetative compatibility types in populations of Eutypa lata from grapevines. J Plant Pathol 83: 79-86.

Cortesi P, Milgroom MG, Bisiach M (1996). Distribution and diversity of vegetative compatibility types in subpopulations of Cryphonectria parasitica in Italy. Mycol Res 100: $1087-1093$.

Ellstrand NC, Torres AM, Levin DA (1978). Density and the rate of apparent outcrossing in Helianthus annuus (Asteraceae). Syst Bot 3: 403-407.

Ennos RA, Swales KW (1987). Estimation of the mating system in a fungal pathogen Crumenulopsis sororia (Karst.) Groves using isozyme markers. Heredity 59: 423-430.

Fischer M (1996). On the species complexes within Phellinus: Fomitoporia revisited. Mycol Res 100: 1459-1467.

Harrington TC, McNew DL (1997). Self-fertility and unidirectional mating-type switching in Ceratocystis coerulescens, a filamentous ascomycete. Curr Genet 32: 52-59.

Herskowitz I (1988). Life cycle of the budding yeast Saccharomyces cerevisiae. Microbiol Rev 52: 536-553. 
Holsinger KE (1986). Dispersal and plant mating systems: the evolution of self-fertilization in subdivided populations. Evolution 40: 405-413.

Holsinger KE (1991). Mass action models of plant mating systems: the evolutionary stability of mixed mating systems. Am Nat 138: 606-622.

Hood M, Antonovics J (2000). Intratetrad mating, heterozygosity, and the maintenance of deleterious alleles in Microbotryum violaceum. Heredity 85: 231-241.

Jain SK (1976). The evolution of inbreeding in plants. Annu Rev Ecol Syst 7: 69-95.

Kaltz O, Shykoff JA (1999). Selfing versus outcrossing propensity of the fungal pathogen Microbotryum violaceum across Silene latifolia host plants. J Evol Biol 12: 340-349.

Karron JD, Thumser NN, Tucker R, Hesenauer AJ (1995). The influence of population density on outcrossing rates in Mimulus ringens. Heredity 75: 175-180.

Kauserud H, Schumacher T (2001). Outcrossing or inbreeding: DNA markers provide evidence for type of reproductive mode in Phellinus nigrolimitatus. Mycol Res 105: 676-683.

Kohli Y, Kohn LM (1992). In vitro and in vivo outbreeding studies on Sclerotinia sclerotiorum. Newslett Mycol Soc Am 43: 39 (abstract).

Kohn LM, Stasovski E, Carbone I, Royer J, Anderson JB (1991). Mycelial incompatibility and molecular markers identify genetic variability in field populations of Sclerotinia sclerotiorum. Phytopathology 81: 480-485.

Kroken S (2001). Outcrossing and recombination in the lichenized fungus Letharia. Fungal Genet Biol 34: 83-92.

Lande R, Schemske DW (1985). The evolution of self-fertilization and inbreeding depression in plants I. Genetic models. Evolution 39: 24-40.

Leslie JF, Raju NB (1985). Recessive mutations from natural populations of Neurospora crassa that are expressed in the sexual diplophase. Genetics 111: 59-77.

Linder-Basso D, Foglia R, Zhu P, Hillman BI (2001). Crypt1, an active Ac-like transposon from the chestnut blight fungus, Cryphonectria parasitica. Mol Genet Genom 265: 730-738.

Lipow SR, Broyles SB, Wyatt R (1999). Population differences in self-fertility in the 'self-compatible' milkweed Asclepias exaltata (Asclepiadaceae). Am J Bot 86: 1114-1120.

Liu Y-C, Hillman BI, Linder-Basso D, Kaneko S, Milgroom MG (2003). Evidence for interspecies transmission of viruses in natural populations of filamentous fungi in the genus Cryphonectria. Mol Ecol 12: 1619-1628.

Lloyd DG (1967). The genetics of self-incompatibility in Leavenworthia crassa Rollins (Cruciferae). Genetica 38: 227-242.

Marra RE, Milgroom MG (2001). The mating system of the fungus Cryphonectria parasitica: selfing and self-incompatibility. Heredity 86: 134-143.

Mathieson MJ (1952). Ascospore dimorphism and mating type in Chromocrea spinulosa. Ann Bot NS 16: 449-466.

McGuire IC, Marra RE, Milgroom MG (2004). Mating-type heterokaryosis and selfing in Cryphonectria parasitica. Fungal Genet Biol 41: 521-533.

McGuire IC, Marra RE, Turgeon BG, Milgroom MG (2001). Analysis of mating-type genes in the chestnut blight fungus, Cryphonectria parasitica. Fungal Genet Biol 34: 131-144.

Milgroom MG, Cortesi P (1999). Analysis of population structure of the chestnut blight fungus based on vegetative incompatibility genotypes. Proc Natl Acad Sci USA 96: 10518-10523.

Milgroom MG, Lipari SE (1995). Spatial analysis of nuclear and mitochondrial RFLP genotypes in populations of the chestnut blight fungus, Cryphonectria parasitica. Mol Ecol 4: 633-642.

Milgroom MG, Lipari SE, Ennos RA, Liu Y-C (1993). Estimation of the outcrossing rate in the chestnut blight fungus, Cryphonectria parasitica. Heredity 70: 385-392.
Milgroom MG, Lipari SE, Powell WA (1992). DNA fingerprinting and analysis of population structure in the chestnut blight fungus, Cryphonectria parasitica. Genetics 131: 297-306.

Murawski DA, Hamrick JL (1991). The effect of the density of flowering individuals on the mating systems of nine tropical tree species. Heredity 67: 167-174.

Neale DB, Adams WT (1985). Allozyme and mating-system variation in balsam fir (Abies balsamea) across a continuous elevational transect. Can J Bot 63: 2448-2453.

Pascarella JB (1997). The mating system of the tropical understory shrub Ardisia escallonioides (Myrsinaceae). Am Bot 84: 456-460.

Perkins D (1987). Mating-type switching in filamentous ascomycetes. Genetics 115: 215-216.

Richards AJ (1997). Plant Breeding Systems. 2nd edn. Chapman \& Hall: London.

Rick CM, Holle M, Thorp RW (1978). Rates of cross-pollination in Lycopersicon pimpinellifolium: Impact of genetic variation in floral characters. Plant Syst Evol 129: 31-44.

Ronfort J, Couvet D (1995). A stochastic model for selection on selfing rates in structured populations. Genet Res 65: 209-222.

Schemske DW, Lande R (1985). The evolution of self-fertilization and inbreeding depression in plants II. Empirical observations. Evolution 39: 41-52.

Schoen DJ (1982). The breeding system of Gilia achilleifolia: variation in floral characteristics and outrossing rate. Evolution 36: 352-360.

Sharland PR, Rayner ADM (1989a). Mycelial interactions in outcrossing populations of Hypoxylon. Mycol Res 93: 187-198

Sharland PR, Rayner ADM (1989b). Mycelial ontogeny and interactions in non-outcrossing populations of Hypoxylon. Mycol Res 93: 273-281.

Sharland PR, Rayner ADM, Ofong AU, Barrett DK (1988). Population structure of Rosellina desmatzieresii causing ringdying in Salix replus. Trans Br Mycol Soc 90: 654-656.

Shaw DV, Kahler AL, Allard RW (1981). A multilocus estimator of mating system parameters in plant populations. Proc Natl Acad Sci USA 78: 1298-1302.

Shea KL (1987). Effects of population structure and cone production on outcrossing rates in Engelmann spruce and sub-Alpine fir. Evolution 41: 124-136.

Uhm JY, Fujii H (1983). Heterothallism and mating type mutations in Sclerotinia trifoliorum. Phytopathology 73: $569-572$.

Uyenoyama MK, Holsinger KE, Waller DM (1993). Ecological and genetical factors directing the evolution of self-fertilization. Oxford Surv Evol Biol 9: 327-381.

Vasek FC, Harding J (1976). Outcrossing in natural populations. V. Analysis of outcrossing, inbreeding, and selection in Clarkia exilis and Clarkia trembloriensis. Evolution 30: 403-411.

Waller DM (1986). Is there disruptive selection for selffertilization? Am Nat 128: 421-426.

Wang X-R (1997). Genetic variability in the canker pathogen fungus, Gremmeniella abietina. Contribution of sexual compared with asexual reproduction. Mycol Res 101: 1195-1201.

Wikler K, Gordon TR (2000). An initial assessment of genetic relationships among populations of Fusarium circinatum in different parts of the world. Can J Bot 78: 709-717.

Wikler K, Gordon TR, Clark SL, Wingfield MJ, Britz H (2000). Potential for outcrossing in an apparently asexual population of Fusarium circinatum, the causal agent of pitch canker disease. Mycologia 92: 1085-1090.

Wolff K, Friso B, van Damme JMM (1988). Outcrossing rates and male sterility in natural populations of Plantago coronopus. Theor Appl Genet 76: 190-196.

Yun S-H, Berbee ML, Yoder OC, Turgeon BG (1999). Evolution of the fungal self-fertile reproductive life style from selfsterile ancestors. Proc Natl Acad Sci USA 96: 5592-5597. 